University of South Carolina

Scholar Commons

\title{
Effects of a Smaller Unit Cell Planar EBG Structure on the Mutual Coupling of a Printed Dipole Array
}

\author{
M. Faisal Abedin \\ University of South Carolina - Columbia \\ Mohammod Ali \\ University of South Carolina - Columbia, alimo@engr.sc.edu
}

Follow this and additional works at: https://scholarcommons.sc.edu/elct_facpub

Part of the Electrical and Computer Engineering Commons

\footnotetext{
Publication Info

Published in IEEE Antennas and Wireless Propagation Letters, Volume 4, 2005, pages 274-276.

http://ieeexplore.ieee.org/xpl/Recentlssue.jsp?reload=true\&punumber=7727

(C) 2005 by IEEE
}

This Article is brought to you by the Electrical Engineering, Department of at Scholar Commons. It has been accepted for inclusion in Faculty Publications by an authorized administrator of Scholar Commons. For more information, please contact digres@mailbox.sc.edu. 


\title{
Effects of a Smaller Unit Cell Planar EBG Structure on the Mutual Coupling of a Printed Dipole Array
}

\author{
M. F. Abedin, Student Member, IEEE and M. Ali, Senior Member, IEEE
}

\begin{abstract}
A new smaller unit-cell planar electromagnetic bandgap (EBG) structure is proposed on low dielectric constant low-cost substrate (TMM: $\varepsilon_{\mathrm{r}}=4.5$, thickness $\left.=25 \mathrm{mils}\right)$ that has a stopband frequency at around $4 \mathrm{GHz}$. The proposed structure when placed in between a two-element printed dipole array results in over 13-dB reduction in mutual coupling and a significant improvement in antenna return loss bandwidth and gain pattern.
\end{abstract}

Index Terms-Antenna array, mutual coupling, planar electromagnetic bandgap (EBG), surface wave.

\section{INTRODUCTION}

$\mathbf{P}$ RINTED ANTENNA arrays suffer from relatively high level of mutual coupling between individual elements due to surface waves [1]. This becomes progressively worse with increasing frequency, dielectric constant, and substrate thickness. Excessive mutual coupling between elements can confine the angular scanning region in an array and create blind spots [2]. While mutual coupling can be reduced by increasing the interelement spacing, this results in undesirable grating lobes. Mutual coupling can also be reduced by incorporating electromagnetic bandgap (EBG) structures in between array elements. In [1] a three-dimensional (3-D) mushroom-type EBG structure was used in between microstrip patch elements to achieve $8-\mathrm{dB}$ reduction in mutual coupling. In [3], a uniplanar EBG structure $\left(\varepsilon_{\mathrm{r}}=10.2\right)$ was used to reduce the mutual coupling between probe fed patch antenna elements at $5.75 \mathrm{GHz}$. Undoubtedly planar EBG structures are preferred over 3-D EBGs due to their simplicity and ease of fabrication.

The phenomenal growth of commercial and defense wireless application systems in the lower $\mathrm{GHz}(1.5-6 \mathrm{GHz})$ frequency range calls for efficient low mutual coupling phased arrays and diversity and smart antennas [4], [5] to achieve higher system capacity and increased data rate. Planar EBGs with bandgaps at the lower $\mathrm{GHz}$ frequency range are needed so that they can be used between array elements to reduce mutual coupling. The conventional UC-EBG structures use relatively thick expensive substrates, such as Duroid $6010\left(\varepsilon_{\mathrm{r}}=10.2\right)$ and have stopbands above $10 \mathrm{GHz}$ [6], [7]. UC-EBG structures with lower stopband frequencies can be designed at the expense of thicker substrates, increased unit cell size and, hence, more board space and increased cost. In this letter, we introduce a new geometry on a relatively low dielectric constant low-cost thin substrate (TMM: $\varepsilon_{\mathrm{r}}=4.5$, thickness $=25$ mils) that results in

Manuscript received March 18, 2005; revised June 14, 2005.

The authors are with the Department of Electrical Engineering, University of South Carolina, Columbia, SC 29208 USA (e-mail: alimo@engr.sc.edu).

Digital Object Identifier 10.1109/LAWP.2005.854004

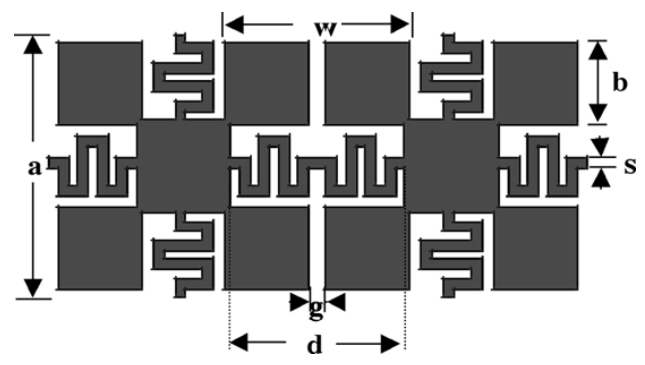

Fig. 1. Two adjacent cells of the proposed planar EBG structure.

EBG stopband frequencies around $4.0 \mathrm{GHz}$ with a considerably smaller unit cell size. We also explore the effect of the proposed planar EBG structure on the mutual coupling between the elements of a dipole array, which has not been investigated before. Since low-profile printed dipole antenna arrays are widely used in man-portable wireless devices, on vehicles, and airborne platforms we compute and measure the mutual coupling between printed dipole elements in the presence of our proposed EBG structure. The EBG structure is so designed that its stopband coincides with the operating frequency of the dipole.

\section{DESIGN OF Planar EBG AND BANDGAP CHARACTERIZATION}

Two adjacent unit cells of the proposed planar EBG structure along with its geometrical parameters are shown in Fig. 1. Each unit cell consists of four square metal plates and four meander-line elements. All of these elements connect to another square metal plate at the center. The meander line elements provide with the necessary inductance while the gap between the adjacent plates generate capacitance. The inductance and capacitance values in turn define the stopband frequency of the EBG structure. The meander line pattern provides with larger values of inductance making it possible to develop an EBG structure with lower stopband frequency and yet smaller cell size.

The proposed EBG structure was studied on a TMM substrate using IE3D, a full-wave method of moments (MoM) solver [8]. The width of the $50 \Omega$ microstripline was 48 mils. Other parameters were $\mathrm{a}=620, \mathrm{~b}=200, \mathrm{~s}=20, \mathrm{~g}=20, \mathrm{w}=420$, and $\mathrm{d}=400$ mils.

To validate performance an EBG structure was fabricated and measured. Photographs of the top and bottom views of the structure are shown in Fig. 2(a) and (b), respectively. Computed and measured $\mathrm{S}_{21}(\mathrm{~dB})$ data for the proposed EBG structure are shown in Fig. 3. A clear stopband is observed between $3.5-4.3 \mathrm{GHz}$, where the insertion loss $\left(\mathrm{S}_{21}\right)$ is lower than $30 \mathrm{~dB}$. The discrepancies between the measured and the 


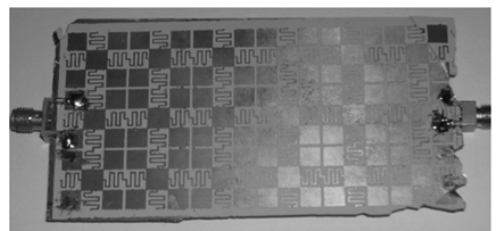

(a)

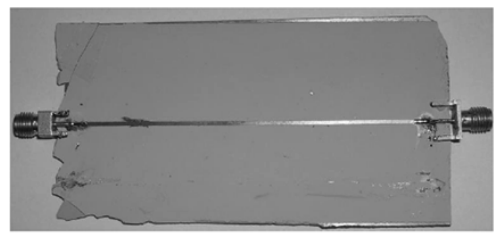

(b)

Fig. 2. Photographs of the fabricated EBG structure along with the microstrip line. (a) Top view. (b) Bottom view.

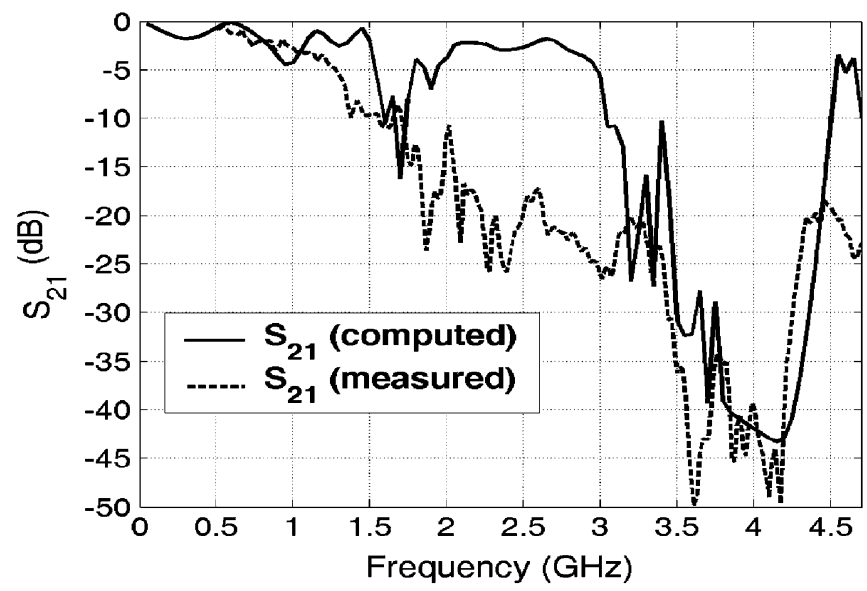

Fig. 3. Computed and measured $\mathrm{S}_{21}(\mathrm{~dB})$ data for the microstripline on the proposed EBG structure $(\mathrm{a}=620$ mils, TMM substrate).

computed data might have been caused due to fabrication imperfection. For comparison a UC-EBG structure with the same cell size and on the same TMM substrate as our proposed one was also simulated. The stopband frequency of the UC-EBG was $7 \mathrm{GHz}$. Thus, a $43 \%$ reduction in stopband frequency was achieved using the proposed EBG structure.

\section{Application of the Proposed Planar EBG: SUPPRESSION OF MUTUAL COUPLING}

\section{A. Dipole Array and EBG Configuration}

The planar EBG structure of Fig. 1 was used in between a two-element printed dipole array to study its effect on antenna mutual coupling, return loss, and radiation pattern.

In Fig. 4(a), a reference antenna array of two printed dipoles is shown without the EBG structure. The same two-element array is also shown in Fig. 4(b) where a single row of the EBG structure consisting of six unit cells is placed in between the dipole elements. In both cases the dipoles were printed on the same TMM substrate on which the EBGs were fabricated on. The only difference was that the reference antenna array was not backed by any metal ground while in the other case only the EBG structure

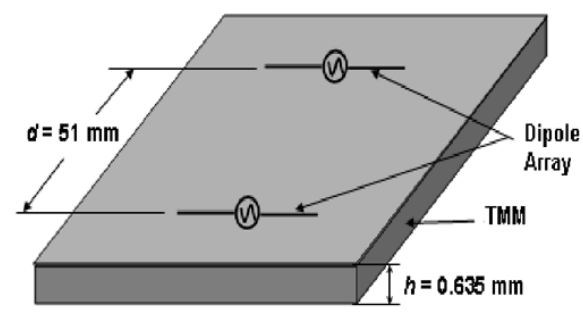

(a)

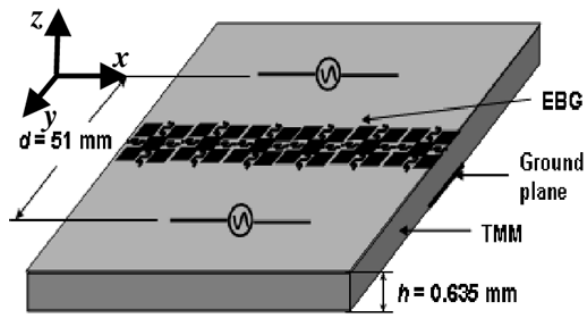

(b)

Fig. 4. Configurations of arrays consisting of two dipole antennas printed on TMM substrate. (a) Conventional case (without EBG). (b) EBG inserted between the dipole elements.

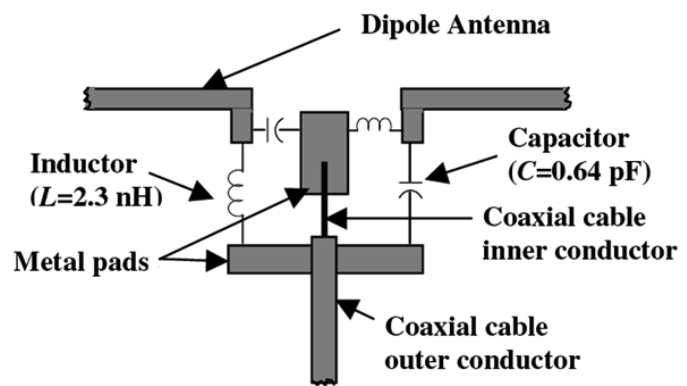

(a)

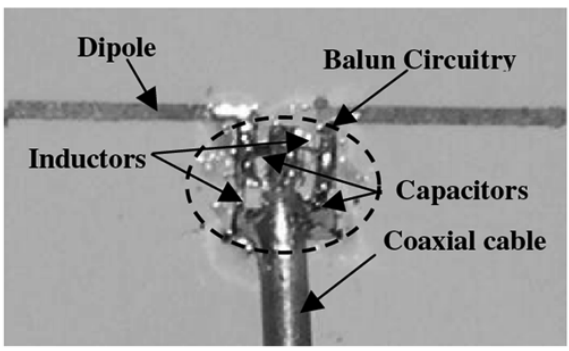

(b)

Fig. 5. (a) Schematic diagram of the lumped-element balun circuit. (b) Photograph of the printed dipole with the balun.

had metallic ground plane below it [see Fig. 4(b)]. Each dipole was constructed with a metal strip with width $1 \mathrm{~mm}$ and was 26 $\mathrm{mm}$ long. The interelement distance $d$ was $51 \mathrm{~mm}$.

The resonant frequency of each printed dipole is at $4.2 \mathrm{GHz}$ which coincides with the stopband frequency of the EBG structure. The dimension of the EBG structure was $94.4 \mathrm{~mm}$ by 15.7 $\mathrm{mm}$. Since the dipole was fed using a coaxial transmission line, a lumped-element balun was also designed as described in [9]. A circuit diagram of the lumped element balun and a photograph of the printed dipole along with the balun circuit are shown in Fig. 5(a) and (b), respectively. 


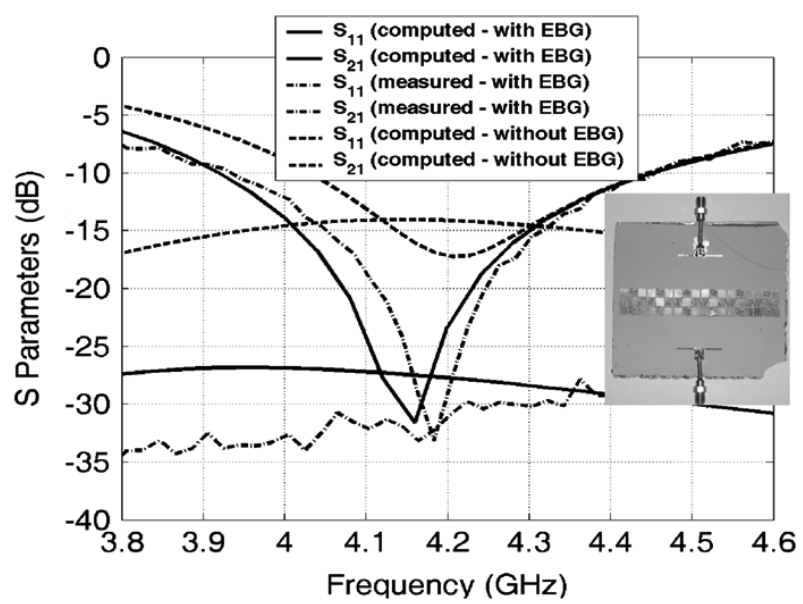

Fig. 6. Computed and measured S-parameters $(\mathrm{dB})$ of the printed dipoles with and without the proposed EBG structure.

\section{B. Computed and Measured Results}

Computed and measured S-parameters for the printed dipoles with the EBG structure are shown in Fig. 6. For comparison computed S-parameters for the printed dipoles of the reference array are also shown in Fig. 6. It is evident that the proposed EBG structure can help achieve a significantly low level of mutual coupling. Mutual coupling $\left(\mathrm{S}_{21}\right)$ with and without the EBG structure are -27 and $-14 \mathrm{~dB}$, respectively. The bandwidth of each printed dipole without the EBG structure is $9.7 \%$, while that with is $12.7 \%$ considering $\mathrm{S}_{11} \leq-10 \mathrm{~dB}$ as the upper limit. The EBG structure increases the antenna bandwidth by $31 \%$.

Computed normalized radiation patterns for the two cases at $4.15 \mathrm{GHz}$ are shown in Fig. 7(a) and (b), respectively. For the reference array without the EBG structure, one can observe blind spots along $\theta= \pm 45^{\circ}$ and grating lobes along $\theta= \pm 70^{\circ}$ and $\theta= \pm 115^{\circ}$. Inclusion of the EBG structure eliminates the blind spots and grating lobes. The array with the EBG structure also shows slightly better gain $(6.7 \mathrm{dBi})$ than without it $(6 \mathrm{dBi})$.

\section{CONCLUSION}

A low-cost planar EBG structure is proposed that can achieve substantially lower stopband frequency than its conventional UC-EBG counterpart. A prototype of the EBG structure along with an array of two dipole elements were fabricated and tested. The computed and measured data showed that the presence of

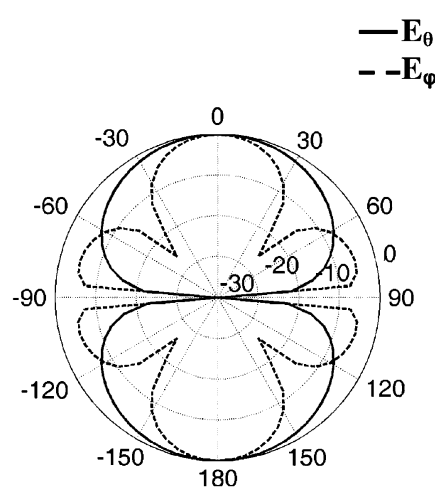

(a)
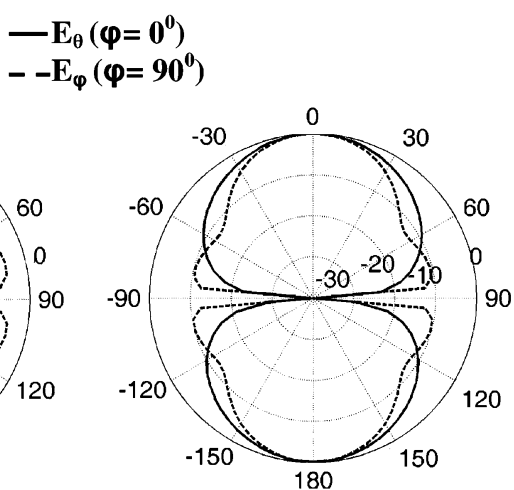

(b)
Fig. 7. Computed normalized radiation patterns of the two-element printed dipole array at $4.15 \mathrm{GHz}$ (a) without EBG and (b) with EBG.

the EBG structure between the array elements reduced the mutual coupling by $13 \mathrm{~dB}$ and increased the antenna bandwidth by $31 \%$. The EBG structure also improved the array performance by eliminating blind spots and grating lobes.

\section{REFERENCES}

[1] F. Yang and Y. Rahmat-Samii, "Microstrip antennas integrated with electromagnetic band-gap (EBG) structures: A low mutual coupling design for array applications," IEEE Trans. Antennas Propag., vol. 51, no. 10, pp. 2939-2949, Oct. 2003.

[2] D. M. Pozar and D. H. Schaubert, "Analysis of an infinite array of rectangular microstrip patches with idealized probes feeds," IEEE Trans. Antennas Propag., vol. AP-32, no. 10, pp. 1101-1107, Oct. 1984.

[3] Z. Iluz, R. Shavit, and R. Bauer, "Microstrip antenna phased array with electromagnetic bandgap substrate," IEEE Trans. Antennas Propag., vol. 52, no. 6, pp. 1446-1453, Jun. 2004.

[4] M. G. Douglas, M. Okoniewski, and M. A. Stuchly, "A planar diversity antenna for handheld PCS devices," IEEE Trans. Veh. Technol., vol. 47, no. 3, pp. 747-754, Aug. 1998.

[5] K. R. Dandekar, H. Ling, and G. Xu, "Effect of mutual coupling on direction finding in smart antenna applications," Electron. Lett., vol. 36, no. 22, pp. 1889-1891, Oct. 2000.

[6] R. Coccioli, F. R. Yang, K. P. Ma, and T. Itoh, "Aperture-coupled patch antenna on UC-PBG substrate," IEEE Trans. Microwave Theory Tech., vol. 47, no. 11, pp. 2123-2130, Nov. 1999.

[7] J. Y. Park, C. C. Chang, Y. Qian, and T. Itoh, "An improved low-profile cavity-backed slot antenna loaded with 2D UC-PBG reflector," in Proc. IEEE Antennas and Propagation Society Symp. Dig., vol. 4, Boston, MA, Jul. 2001, pp. 194-197.

[8] IE3D User's Manual Release 8 [Online]. Available: http://www.zeland.com

[9] P. Vizmuller, RF Design Guide: Systems, Circuits, and Equations. Norwood, MA: Artech House, 1995. 